\title{
ZnAIMg hot-dip galvanised steel sheets Tribology and tool wear
}

\author{
A.E. Raab, E. Berger, J. Freudenthaler, F. Leomann, C. Walch
}

For the last few years zinc magnesium alloys on cold rolled steel were investigated in detail because of their potential to provide better corrosion protection than pure zinc coatings [1]. However, for introduction into the automotive industry, it is also necessary to learn more about their tribological behavior. In the present work the tribological potential of ZnAlMg hot dip galvanized steel sheets (HDG/ZM) was studied in terms of sliding properties, adhesive and abrasive tool wear and compared to hot dip galvanized reference material (HDG/Z). Different tribological tests were performed. The friction coefficient was determined directly by doing strip draw tests at constant contact pressure. The deep drawing property was tested by forming model cups. Two different oils, a pure corrosion protection oil and a prelube, were tested in each of the tribological tests. Abrasive tool

wear was studied according to the SEP1160 standard. Adhesive tool wear (galling) was characterized on different tool material and compared to the results for hot dip galvanized reference material. HDG/ZM strips

showed improved friction behavior in the strip draw test when compared to classical hot dip galvanized reference material. The abrasive tool wear is comparable to HDG/Z material, however, the galling was found to

be less than for pure zinc, and the morphology of the coating material transferred to the tool during deep drawing is also different. This makes HDG//ZM an interesting system not only with respect to corrosion but also in terms of tribology, thus providing clear advantages in formability.

Keywords:

ZnAlMg, zinc magnesium, tribology, tool wear, galling, adhesive tool wear

\section{INTRODUCTION}

Zinc magnesium coatings on cold rolled steel have become more and more important in recent years[2,3], especially in the construction industry. This is mainly due to improved corrosion performance when compared to classical hot dip galvanized steel $[4,5]$, which permits a reduction in coating thickness in some applications. The automotive industry has also become more interested in the new material, mainly because of advantages in corrosion performance, but also because of material test results that indicate the advantages of tribology and tool wear.

Hot dip galvanized zinc magnesium coatings (HDG/ZM) do not consist of a single phase throughout the coating thickness but show a complex composition [6] of different phases (see Fig. 1). Also the hardness of the coating is affected by adding magnesium. While hardness of a classical zinc coating is about 70-90 HV0.02, the hardness of HDG/ZM (2\% Al and $2 \% \mathrm{Mg})$ is in a range of 130-160HV0.02. All these differences to classical hot dip galvanized zinc coatings (HDG/Z) have an influence on the processing properties of the new material, among them tribology and tool wear. Tribological and tool wear tests have to be conducted prior to introducing the new material to the automotive industry. Some of these studies, at least with respect to model parts, are presented and discussed in this paper.

A.E. Raab, E. Berger, J. Freudenthaler, F. Leomann, C. Walch voestalpine Stahl GmbH, Linz,Austria

Paper presented at the $8^{\text {th }}$ Int. Conf. GALVATECH 2011, Genova, 21-25 June 2011, organized by AIM
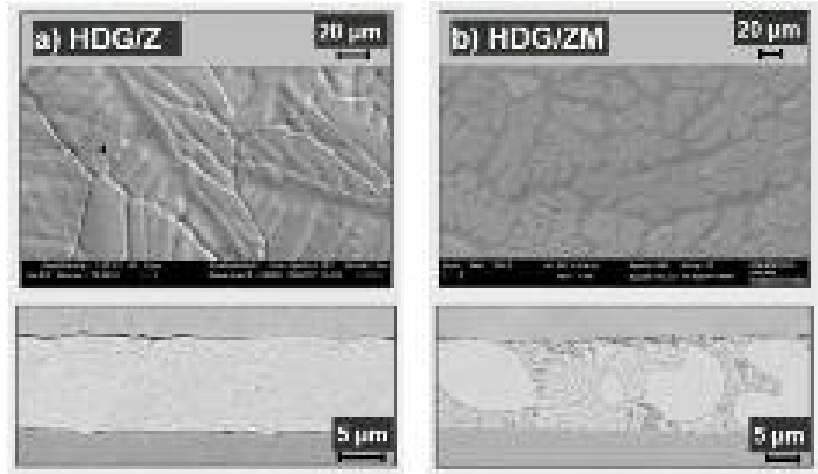

FIG. 1 a) Scanning electron microscopy (SEM) image of top view and cross section of a standard hot dip galvanized steel coating. The coating is widely homogeneous in composition over its thickness, and the top view shows the typical morphology of a hot dip galvanized surface. b) SEM image of top view and cross section of a HDG/ZM surface. In contrast to HDG/Z, HDG/ZM shows a complex composition of different $\mathrm{ZnMg}$ phases throughout the coating.

a) Immagine SEM della vista frontale e della sezione trasversale di un rivestimento standard di acciaio galvanizzato a caldo. Il rivestimento è molto omogeneo quanto a composizione per tutto lo spessore e la vista frontale mostra la tipica morfologia di una superficie galvanizzata a caldo. b) Immagine SEM frontale e della sezione trasversale di un rivestimento HDG/ZM. Rispetto alla $H D G / Z$, la $H D G / Z M$ mostra una compisizione complessa delle diverse fasi $\mathrm{ZnMg}$ attraverso l'intero rivestimento. 


\section{MATERIALS AND METHODS}

Each of the tests presented in this work were conducted using mild cold rolled steel coated with classical zinc or with zinc magnesium alloy produced in an industrial hot dip galvanizing line. An amount of $2 \% \mathrm{Mg}$ and $2 \% \mathrm{Al}$ is added in the liquid zinc melt for the production of the zinc magnesium alloy. The surface roughness of both HDG/Z and HDG/ZM is about $\mathrm{Ra}=1.0-1.2 \mu \mathrm{m}$ and $\mathrm{Rz}=5.5-6.4 \mu \mathrm{m}$. In the case of HDG/ZM, two different coating weights were tested, $100 \mathrm{~g} / \mathrm{m}^{2}$ (HDG/ZM100 or ZM100) and $200 \mathrm{~g} / \mathrm{m}^{2}$ (HDG/ZM200 or ZM200). The reference material had a zinc coating weight of $100 \mathrm{~g} / \mathrm{m}^{2}$ (HDG/Z100 or Z100). The steel characteristics were tested parallel to the rolling direction and were measured as follows: Rp02=157-160MPa, Rm=290-300 MPa. For tribological tests and tool wear, the steel sheets were cleaned with acetone and oiled freshly with $1.5 \mathrm{~g} / \mathrm{m}^{2}$ Multidraw PL61 (PL) or Anticorit RP 4107 S (CPO). Multidraw PL61 was taken as a representative for prelubes, whereas Anticorit RP $4107 \mathrm{~S}$ was used as a representative for pure corrosion protection oils.

\section{Strip Draw Test}

For the strip draw test a specially designed testing unit is installed on a tensile testing machine. The clamping force is applied by means of a hydraulic system, and the tensile testing machine draws the strip trough a clamping tool while measuring the drawing force. The geometry of the clamping tool is variable. In the presented tests, two different clamping tools were used, the flat tool geometry for determination of friction coefficient (see Figure 2a) and the wear tool [7], which consists of a flat tool and a cylindrical tool of $20 \mathrm{~mm}$ in diameter (see Figure $2 b)$. The tool roughness was $R a=0.4 \mu \mathrm{m}$ for all tools used for the strip draw test.

\section{Determination of friction coefficient}

The flat tool geometry was used to determine the friction coefficient. The tool material is tool steel 1.2379 hardened to $60 \mathrm{HRC}$. The direction of tool polishing was parallel to draw direction, as it is for most surfaces in real automotive tools. The draw length of each strip was $240 \mathrm{~mm}$ and the strip width was $50 \mathrm{~mm}$. Two different draw speeds were used, $3 \mathrm{~mm} / \mathrm{s}$ and $50 \mathrm{~mm} / \mathrm{s}$. The contact pressure used for the testing was $6.67 \mathrm{~N} / \mathrm{mm}^{2}$ and 13.33 $\mathrm{N} / \mathrm{mm}^{2}$.

\section{Determination of tool wear}

The abrasive and adhesive tool wear (galling) was tested with a special wear tool geometry [7]. A photograph of the tool is shown in Figure 2b. The tool is asymmetric with a flat tool on one side and a round shaped tool on the other, resulting in a line contact. The flat side of the tool is characterized for evaluation in terms of tool wear by measuring either 2D profiles on 3 fixed positions (abrasive tool wear) or inspecting the transfer of coating material to the tool surface (adhesive tool wear). The tool material for the tool abrasion test is unhardened tool steel 1.2344 that is very sensitive to tool abrasion and leads, in contrast to tool material used in real automotive tools, to measurable abrasion even in the rather short draw length of $15 \mathrm{~m}$. The results obtained on 1.2344 reflect very well the abrasion behavior found in real automotive tools, and the material ranking of 1.2344 corresponds very well to the ranking found in real automotive tools [7]. Both EN-GJL-200 and EN-GJS-700 are used as tool material in the flat tool for the galling test. The first is used for low volume parts because it limits the tool costs. The latter is widely used in deep drawing applications in the automotive industry as an economic choice with sufficiently good drawing properties for high volume parts. Both materials were used unhardened because this is the

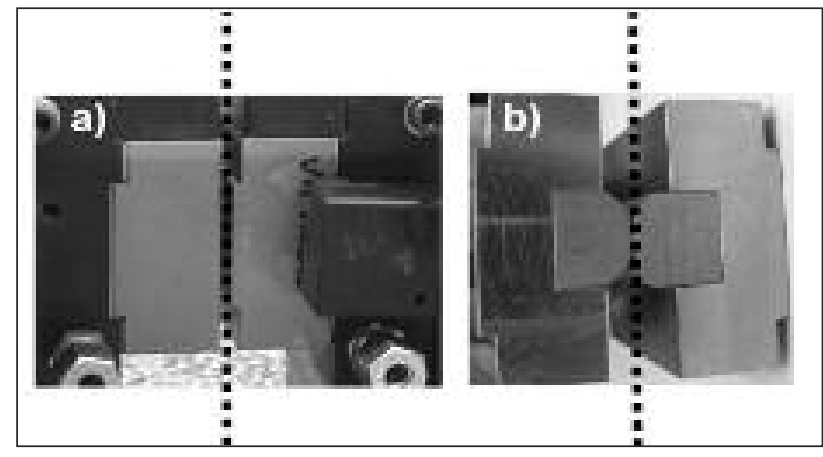

FIG. 2 Photograph of the two different tool geometries used in the strip draw test. The position of the steel strip is indicated by the dashed line. The contact pressure is applied perpendicular to the steel strip. a) flat tool geometry used for determination of friction coefficient. b) tool geometry used for abrasive and adhesive tool wear test.

Immagine delle due diverse geometrie di utensile utilizzate nella prova di strip draw. La posizione della lamiera di acciaio è indicata dalla linea tratteggiata. La pressione di contatto è applicata perpendicolarmente alla lamiera di acciaio. a) geometria di utensile piatto utilizzata per determinare il coefficiente di frizione. b) geometria dell'utensile utilizzata per le prove di abrasione e adesione con l'utensile.

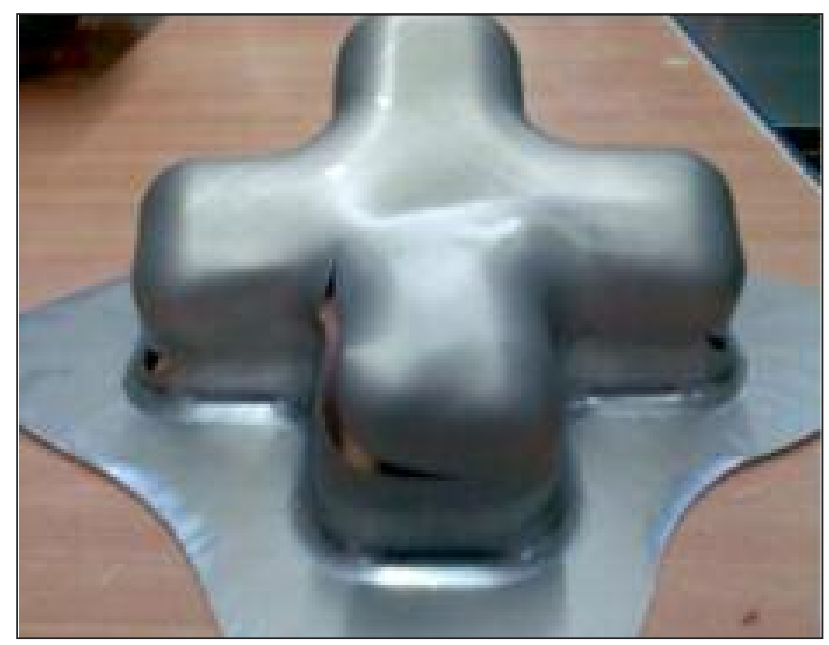

FIG. 3 Photograph of the cross die part. This tool was used for deep drawing experiments at more complex forming states. For characterizing the tribology, both, the maximum draw depth at a fixed blank holder force and the draw force are measured.

Immagine dello stampo a croce. Questo utensile è stato utilizzato per gli esperimenti di imbutitura profonda negli stati di formatura più complessi. Per la caratterizzazione tribologica sono state misurate sia la profondità massima di imbutitura a una forza fissa di premilamiera (BHF - blank holder force) che lo sforzo di imbutitura. 


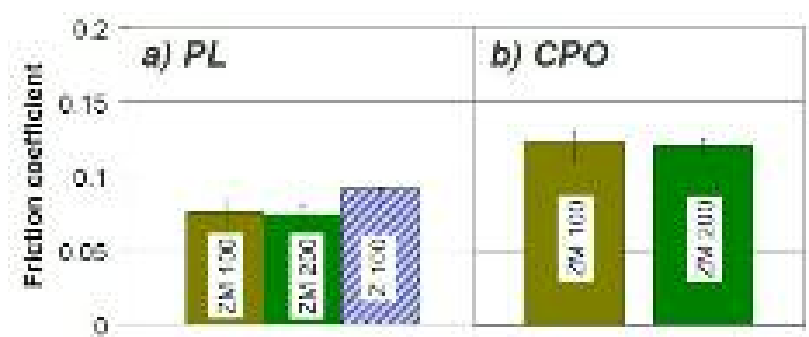

FIG. 4 Friction coefficient measured at a contact pressure of $6.67 \mathrm{~N} / \mathrm{mm}^{2}$ and $50 \mathrm{~mm} / \mathrm{s}$ draw speed.

Coefficiente di frizione misurato a una pressione di contatto di $6.67 \mathrm{~N} / \mathrm{mm}^{2}$ e velocità di imbuttitura di 50 $\mathrm{mm} / \mathrm{s}$.

more critical state. The overall draw length for the galling test was $2.4 \mathrm{~m}$. The direction of tool polishing was perpendicular to draw direction for both the abrasive and adhesive tool wear test because this is the most critical configuration in both cases. The draw speed was $25 \mathrm{~mm} / \mathrm{s}$ and the clamping force was $5 \mathrm{kN}$.

\section{Model Cups}

Model cups were formed for testing the deep drawing properties in a real forming tool. The blanks were cleaned with acetone and oiled freshly prior to deep drawing. The diameter of the cups was $33 \mathrm{~mm}$, the ratio beta=blank diameter/punch diameter was 2.06. The blank holder force was increased stepwise from 20 to $240 \mathrm{kN}$. The draw speed was $3 \mathrm{~mm} / \mathrm{s}$ and $100 \mathrm{~mm} / \mathrm{s}$. The cross die tool was used (see Figure 3) to form parts with more critical forming states. The blanks were cleaned as described above and formed at a blank holder force of $300 \mathrm{kN}$ and $3 \mathrm{~mm} / \mathrm{s}$ draw speed. The maximum draw depth and draw forces were measured and compared.
RESULTS AND DISCUSSION

The friction coefficient of HDG/ZM (HDG/ZM100 and HDG/ZM200) was measured for the two different types of oil (prelube and corrosion protection oil) and at four combinations of draw parameters. The results are listed in Table 1 and compared to the results for HDG/Z. The most

obvious result is that HDG/ZM can be drawn at more different draw parameters without slip-stick than HDG/Z. For HDG/Z a measurement without slip-stick is only possible for one of the four different draw parameter sets tested, which is prelube (PL) for oiling and the parameter combination of $6.67 \mathrm{~N} / \mathrm{mm}^{2}$ contact pressure and $50 \mathrm{~mm} / \mathrm{s}$ draw speed. For the pure corrosion protection oil (CPO) none of the four parameter combinations could be drawn without slip-stick when HDG/Z was used. The situation is different for HDG/ZM. For both oils, PL and CPO, three different parameter sets out of four were drawn without slipstick. The tribology of HDG/ZM is better than that of HDG/Z as indicated by the facts that the base material has a negligible influence on the results in the strip draw test and the surface topography is comparable in all three materials.

In Figure 4 the measured friction coefficients are compared at a contact pressure of $6.67 \mathrm{~N} / \mathrm{mm}^{2}$ and $50 \mathrm{~mm} / \mathrm{s}$ draw speed for PL and CPO. HDG/Z is drawable only when PL is used for oiling (see Fig. 4a) and is therefore absent in Fig. 4b). The measured friction coefficient of HDG/Z is slightly higher than that of HDG/ZM, although the differences in values are not very high. The values for ZM100 and ZM200 are almost the same for both oils, PL and CPO, indicating that the coating thickness has no influence on the friction coefficient. However, the friction coefficients measured for oiling with PL are lower for all coatings than the friction coefficients measured when CPO is used, which is evident because CPO is not optimized for drawing. This is in contrast to PL, which contains additives that optimize the tribological behavior of the oil.

When a prelube is used (a) HDG/Z (Z100) can be drawn without slip-stick. However, the friction coefficient is slightly higher than

\begin{tabular}{|c|c|c|c|c|c|c|}
\hline \multirow{2}{*}{$\begin{array}{l}\text { Contact } \\
\text { Pressure, } \\
\text { Draw Speed }\end{array}$} & \multicolumn{3}{|c|}{ Prelube (PL) } & \multicolumn{3}{|c|}{ Corrosion protection oil (CPO) } \\
\hline & $\begin{array}{l}\text { HDG/ZM } 10 \\
0\end{array}$ & $\begin{array}{l}\text { HDG/ZM20 } \\
0\end{array}$ & HDG /Z100 & $\begin{array}{l}\text { HDG /ZM } 10 \\
0\end{array}$ & $\begin{array}{l}\text { HDG /ZM20 } \\
0\end{array}$ & HDG $/ Z 100$ \\
\hline $\begin{array}{l}6.67 \mathrm{~N} / \mathrm{mm}^{2}, \\
3 \mathrm{~mm} / \mathrm{s}\end{array}$ & $0.087-0.096$ & $0.091-0.106$ & Slip-Stick & $0.14-0.155$ & $0.13-0.1356$ & Slip-Stick \\
\hline $\begin{array}{l}6.67 \mathrm{~N} / \mathrm{mm}^{2}, \\
50 \mathrm{~mm} / \mathrm{s}\end{array}$ & $0.06-0.08$ & $0.065-0.080$ & $0.086-0.092$ & $0.11-0.13$ & $0.115-0.124$ & Slip-Stick \\
\hline $\begin{array}{l}13.33 \mathrm{~N} / \mathrm{mm}^{2} \text {, } \\
3 \mathrm{~mm} / \mathrm{s}\end{array}$ & Slip-Stick & Slip-Stick & Slip-Stick & Slip-Stick & Slip-Stick & Slip-Stick \\
\hline $\begin{array}{l}13.33 \mathrm{~N} / \mathrm{mm}^{2} \text {, } \\
50 \mathrm{~mm} / \mathrm{s}\end{array}$ & $0.059-0.071$ & $0.07-0.080$ & Slip-Stick & $0.114-0.126$ & $0.108-0.122$ & Slip-Stick \\
\hline
\end{tabular}

TAB. 1 Friction coefficient determined in the strip draw test for HDG/Z and HDG/ZM at two different coating weights (HDG/ZM100 and HDG/ZM200). Two different oils were used, a pure corrosion protection oil (CPO) and a prelube (PL). Four different combinations of contact pressure and draw speed were tested. HDG/Z reference material can only be drawn without any slip-stick at $6.67 \mathrm{~N} / \mathrm{mm}^{2}$ and $50 \mathrm{~mm} / \mathrm{s}$ draw speed when a prelube is used. In contrast, HDG/ZM can be drawn without slip-stick for three different parameter sets and for both oils. However the friction coefficient when a corrosion protection oil is used is higher than for a prelube.

Coefficiente di frizione determinato nel test strip draw per HDG/Z e HDG/ZM in due diverse quantità di deposito (HDG/ZM100 and HDG/ZM200). Sono stati utilizzati due oli diversi: uno puro di protezione contro la corrosione (CPO) e un olio Prelube (PL). Sono state indagate quattro diverse combinazioni tra pressione di contatto e velocità di transito. II materiale di riferimento HDG/Z può essere processato senza difetti superficiali (slip-stick) a $6.67 \mathrm{~N} / \mathrm{mm}^{2}$ e $50 \mathrm{~mm} / \mathrm{s}$ di velocità, utilizzando il Prelube. HDG/ZM, invece, può essere processato senza comparsa di difetti contre diverse combinazioni di parametri e con entrambi gli oli. Comunque il coefficiente di frizione risulta più alto con l'olio protettivo se confrontato con il Prelube. 
it is for HDG/ZM (ZM100 and ZM200). When a pure corrosion protection oil is used (b), only HDG/ZM can be drawn without slipstick. To compare the friction coefficient measured for the two different oils, the friction coefficient for HDG/ZM in the case of CPO is slightly higher than for PL, which is optimized for deep drawing applications.

Figure 5 compares the friction coefficients at $13.33 \mathrm{~N} / \mathrm{mm}^{2}$ contact pressure and $50 \mathrm{~mm} / \mathrm{s}$ draw speed. For both oils HDG/Z can not be drawn without slip-stick. In contrast, HDG/ZM can be drawn and leads to stable results for the friction coefficient. The results for the friction coefficient differ not much from the results shown in fig. 4 , indicating that in terms of contact pressure the coating system is quite stable. Again the results for ZM100 and ZM200 are comparable whereas the measured friction coefficient for CPO is higher than the results for using a prelube optimized for drawing applications.

Model cups were formed in the next step. This permits some predictions about the deep drawing behavior of the material. In contrast to the strip draw test, where the influence of the properties of the steel beneath the coating can be widely neglected, the deep drawing properties detected by forming model cups depend not only on the tribology of the surface but also on the formability of the steel substrate. Therefore it is important that the steel characteristics of all materials tested are the same so that differences in drawability can be referred to as differences in tribology. This criterion is met for the three materials tested (see Materials and Methods). The results of the drawing test are shown in $\mathrm{Fi}-$ gure 6 . Both types of oil, the pure corrosion protection oil and the prelube oil, were used in the deep drawing test and the results were compared. The blank holder force was increased stepwise from $20-240 \mathrm{kN}$ and the cups were drawn until cracking became apparent. The maximum draw depth until crack was measured and plotted as a function of blank holder force. As the material parameters of the base material are comparable, differences in draw depth at a fixed blank holder force can be attributed to the tribology of the blank. The lower the friction is, the larger the maximum draw depth will be at a fixed blank holder force. The test was performed at two different draw speeds, $3 \mathrm{~mm} / \mathrm{s}$ and 100 $\mathrm{mm} / \mathrm{s}$.

This difference is comparable for both oils. There is a difference at $100 \mathrm{~mm} / \mathrm{s}$ in maximum draw depth found for pure corrosion protection oil, and again the draw depth of HDG/ZM is higher than that of HDG/Z. In contrast, the difference between HDG/ZM and

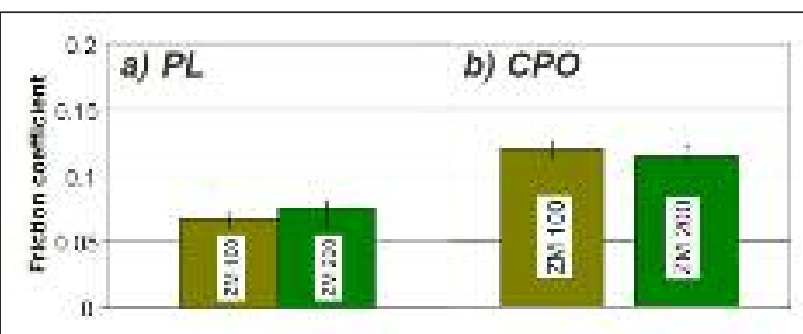

FIG. 5 Friction coefficient measured at a contact pressure of $13.33 \mathrm{~N} / \mathrm{mm}^{2}$ and $50 \mathrm{~mm} / \mathrm{s}$ draw speed. HDG $/ Z$ cannot be drawn without slip-stick for prelube oiling (a) nor for corrosion protection oil (b). However HDG/ZM is still drawable. The measured friction coefficient is clearly smaller when PL is used than it is in the case of CPO.

Coefficiente di frizione misurato a una pressione di contatto di $13.33 \mathrm{~N} / \mathrm{mm}^{2}$ e $50 \mathrm{~mm} / \mathrm{s}$ di velocità di imbutitura. HDG/Z non può essere lavorato senza difetti superficiali (slip-stick) (a) con lubrificazione Prelube e nemmeno (b) con l'olio di protezione dalla corrosione. Invece l'HDG/ZM è ancora sottoponibile a imbutitura. I/ coefficiente di frizione misurato è chiaramente inferiore quando si utilizza PL invece di CPO.

HDG/Z almost vanishes in the case of the prelube, indicating that the differences in tribology between the two materials are almost compensated by the prelube. The material characteristics for all three materials are comparable.

Therefore the higher maximum draw depth measured for HDG/ZM mainly depends on the better tribology of the coating. HDG/ZM at $3 \mathrm{~mm} / \mathrm{s}$ draw speed shows a slightly larger draw depth compared to HDG/Z for both types of oil, PL and CPO, indicating that the tribology of the specific coating dominates the results at this speed. The situation is different at a $100 \mathrm{~mm} / \mathrm{s}$ draw speed. CPO HDG/ZM still achieves a slightly larger draw depth than HDG/Z at a fixed blank holder force, however, the difference between HDG/Z and HDG/ZM is almost negligible for PL. There is still a small tendency for HDG/ZM to achieve a larger draw depth, but the difference between the two draw depths is much smaller than for CPO. This shows that a prelube oil is capable of adap-

FIG. 6

Maximum draw depth as a function of blank holder force for different draw speeds (3mm/s a), b) and $100 \mathrm{~mm} / \mathrm{s} \mathrm{c}), \mathrm{d})$ and different oils (CPO a), c) and $P(b), d)$. The maximum draw depth for a $3 \mathrm{~mm} / \mathrm{s}$ draw speed at a fixed blank holder force is slightly higher for HDG/ZM than for HDG/Z.

Massima profondità di imbutitura in funzione della forza di premilamiera (BHFblank holder force) per diverse velocità di imbutitura (a) e b): $3 \mathrm{~mm} / \mathrm{s} ; \mathrm{c}$ ) e d): 100

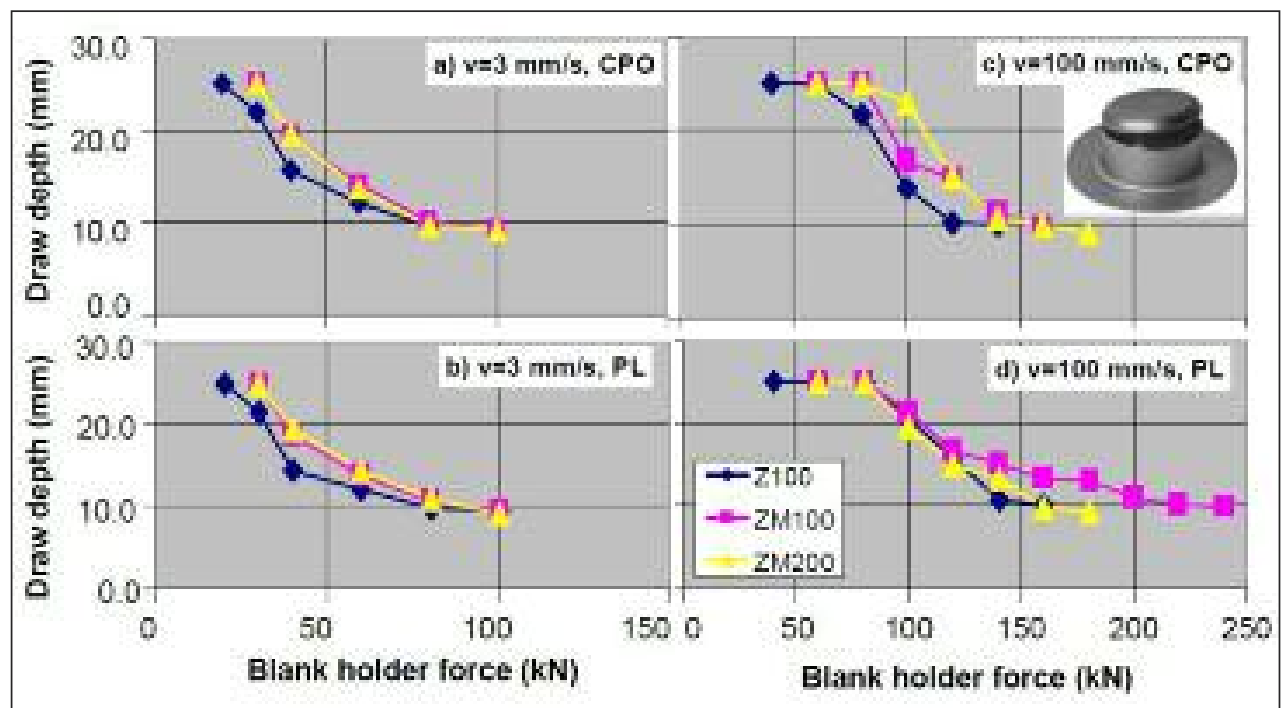

$\mathrm{mm} / \mathrm{s}$ e con diversi olii (a) e c) CPO; b) e d) PL). La massima profondità di imbutitura per una velocità di imbutitura di $3 \mathrm{~mm} / \mathrm{s}$ a una forza di premilamiera BH fissa è leggermente superiore per il rivestimento HDG/ZM rispetto a quello HDG/Z. 


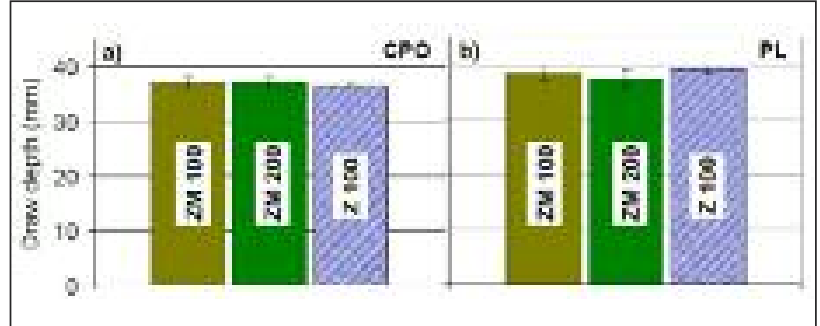

FIG. 7 Maximum draw depth measured in the cross die tool. The draw depth for both HDG/Z and HDG/ZM are comparable, for CPO as well as for PL. The draw depth measured with PL is slightly higher than the one for CPO.

Massima profondità di imbutitura misurata nello stampo a croce. La profondità di imbutitura per i rivestimenti $H D G / Z$ e HDG/ZM sono comparabili, sia per CPO che per PL. La profondità di imbutitura misurata con PL è leggermente più alta che quella per CPO.

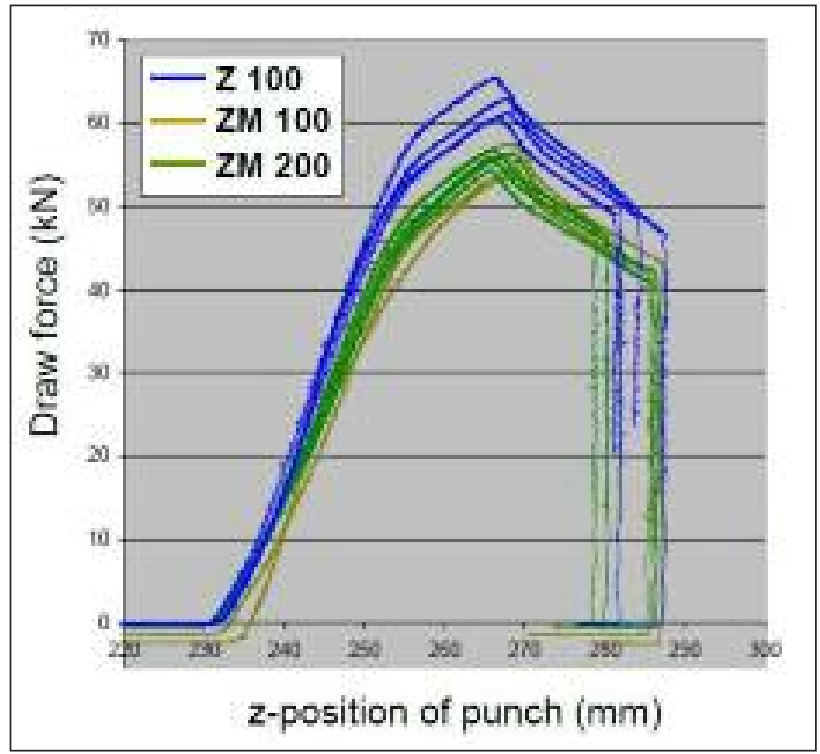

FIG. 8 Draw force as a function of position of punch during drawing. CPO was used for oiling. The draw forces measured for HDG/ZM are lower than those for HDG/Z reflecting the better tribology of HDG/ZM coating material.

Forza di imbutitura in funzione della posizione del punzone durante l' imbutitura. Per la lubrificazione è stato utilizzato CPO. Le forze di imbutitura misurate per $H D G / Z M$ sono minori rispetto a quelle per $H D G / Z$, rispecchiando il miglior comportamento tribologico del materiale di rivestimento $H D G / Z M$.

ting to the differences between the two different coating systems more or less at higher draw speeds. However some advantages of HDG/ZM in terms of tribology still remain at lower draw speeds. These low draw speeds are always found in automotive presses shortly before the press stops and the part is fully formed. Figure 7 shows the maximum draw depth measured for the cross die tool test. The maximum draw depths are comparable for all tested materials. No significant differences were found neither for CPO nor for PL, however, the draw depth for PL are slightly higher, reflecting that the prelube is better adjusted to deep drawing applications.

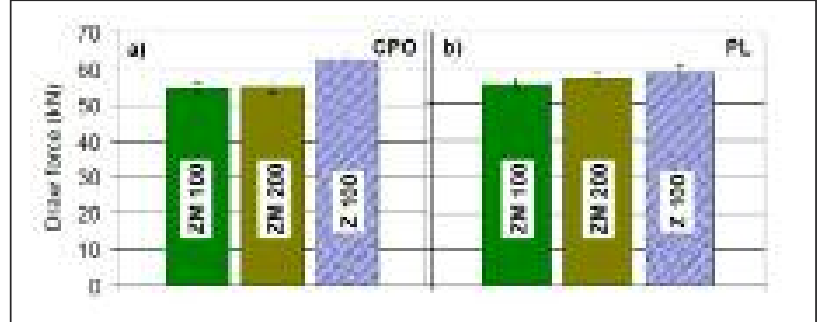

FIG. 9 Draw forces measured for HDG/ZM and HDG/Z reference material for oiling with a) $C P O$ and b) $P L$. The differences in draw force between $H D G / Z M$ and $H D G / Z$ are clearly visible when $C P O$ is used. The draw forces for HDG/ZM are smaller than for $H D G / Z$, reflecting the better tribology of $H D G / Z M$. However, when $P L$ is used, the differences in draw force almost vanish. There is still a small difference in the draw force, but the oil tends to equalize this effect.

Le forze di imbutitura misurate per HDG/ZM e il materiale di riferimento $H D G / Z$ per lubrificazione con a) $C P O$ e b) PL. Le differenze della forza di imbutitura fra $H D G / Z M$ e $H D G / Z$ sono chiaramente visibili quando viene utilizzato $C P O$. Le forze di imbutitura per $H D G / Z M$ sono minori rispetto a $H D G / Z$ rispecchiando il miglior comportamento tribologico del HDG/ZM. Tuttavia se si utilizza PL le differenze nella forza di imbutitura quasi si annullano. Vi è sempre una piccola differenza fra le forze di imbutitura, ma l'olio tende a bilanciare questo effetto.

Figure 8 compares the draw forces measured in the cross die tool as a function of punch position during drawing for CPO. It is clearly visible that the draw force for HDG/ZM is smaller than for HDG/Z. Although there are no significant differences in the maximum draw depth, the draw forces for HDG/ZM are smaller, reflecting again that friction is lower for HDG/ZM than for HDG/Z. The draw forces for the two different types of oil. CPO and PL are compared in Figure 9. Whereas for CPO the difference in draw force is clearly visible (Fig. 9a), the difference between HDG/ZM and $\mathrm{HDG} / \mathrm{Z}$ is smaller when a prelube is used. There is still a small difference, and in the cross die tool test the prelube seems to reduce the differences in tribology between the two materials.

Materials that meet the demands of deep drawing must pass both tribological tests and a number of tool wear tests before they can be considered for automotive applications. One of these tool abrasion tests was conducted with the wear tool of the strip draw test as described in the Materials and Methods section above (SEP1160 standard test [7]). HDG/Z100 was used as a reference material.

The line contact in the wear tool allows a rather simple analysis of a potential tool abrasion, which can be performed by measuring 2D profiles perpendicular to the line contact on the flat tool. If there is any abrasion of the tool material, this can be quantified and compared to other coating materials.

No real tool abrasion was found on the flat tool (results not shown) for HDG/ZM or HDG/Z.

According to the test results, no increased tool wear is expected for HDG/ZM. Smoothing of the initial tool roughness was found on both materials, which is also typical for HDG/Z.

Both tool abrasion and adhesive tool wear (galling) of a new material are important to know. Two different tool materials were used for the test, GJL-200 and GJS-700. A photograph of the tools after the adhesive tool wear test is shown in figure 10. The results 


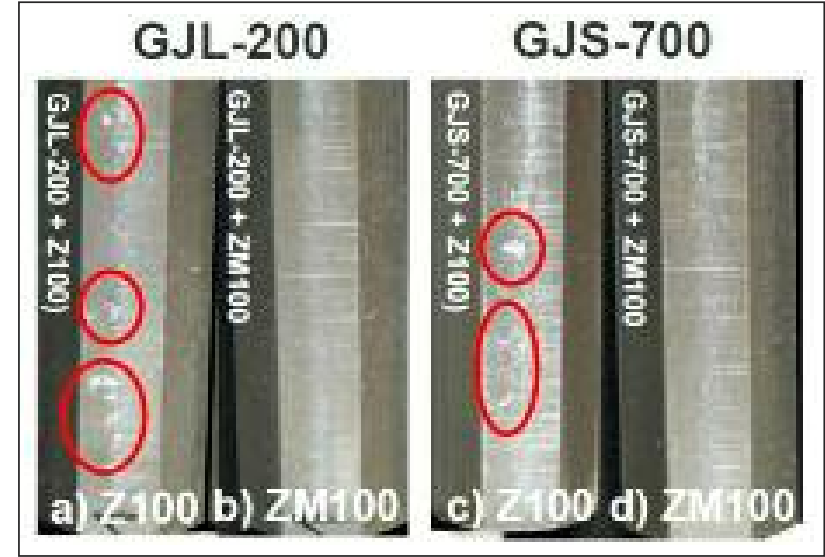

FIG. 10 Adhesive tool wear on GJL-200 and GJS-700 tool material. HDG/Z100 (a) and c) is compared with $H D G / Z M 100$ (b) and d). For both tool materials, GJL-200 and GJS-700, HDG/Z shows the typical flaking. Coating material abraded from the blank surface forms large aggregated Zn-flakes (see a) and c). For HDG/ZM (see b) and d) the adhesive tool wear looks different. No large Zn flakes were observed. The adhesive tool wear looks more powdery and less in amount.

Usura adesiva dell'utensile per materiali da utensile GJL200 e GJS-700. HDG/Z100 (a) e c) sono confrontati con HDG/ZM100 (b) e d). Per entrambi I materiali da utensile, GJL-200 e GJS-700, HDG/Z mostra la tipica scagliatura (flaking). II material di rivestimento abraso dalla superficie sbozzata forma grandi scaglie di Zn aggregate (vedi a) e c)). Per HDG /ZM (vedi b) e d)) l'usura dell'utensile per adesione ha un aspetto diverso. Non sono state osservate grosse scaglie di Zn. II danneggiamento dell'utensile per usura adesiva si presenta più disperso e di minore entità.

for the two different tool materials are almost identical. The typical zinc flakes of the HDG/Z material are visible on both tool materials (marked in red). When HDG/ZM was used, no such flakes were observed. The adhesive tool wear seems to be distributed homogeneously across the contact surface and appears more powdery than in the case of HDG/Z. The total amount of coating material on the tool also seems to be less than in the case of HDG/Z. The difference in adhesive tool wear becomes even clearer when the tool is inspected with a light microscope. Photographs of the tool surface are shown in Figure 11. Big zinc flakes are visible on both HDG/Z-coated blank materials, and no zinc flakes are observed on the HDG/ZM. A certain amount of adhesive tool wear is visible on the tool surface but the morphology is different. The abraded material looks more powdery. Small coating particles can be distinguished and there are no large agglomerates. The total amount of coating material transferred to the tool seems to be less. Finally, the morphology of the coating particles transferred to the surface was studied in the SEM.

The images of two coating particles of comparable size are shown in Figure 12. The HDG/Z particle looks flattened by subsequent drawing, scratches on top of the particle are visible. The structure of the HDG/ZM particle looks more fuzzy. No scratches are visible from subsequent drawing.

After the morphologic tests were completed, the amount of coating material transferred to the tool was determined by removing all coating material from the flat side of the tool by etching in sulfuric acid H2SO4. This makes it possible to determine the ove-

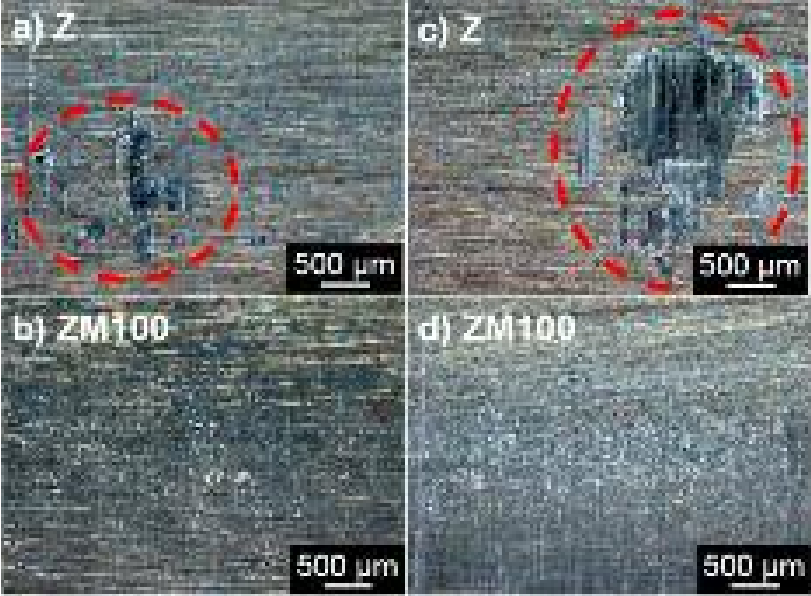

FIG. 11 Microscopic image of adhesive tool wear found on GJL-200 (see a) and b) and GJS-700 (see c) and d). For blanks coated with HDG/Z100 the typical big zinc flakes are visible on the tool surface (marked in red). For blanks coated with HDG/ZM100 the adhesive tool wear looks more powdery, also on the microscopic scale. No big aggregated flakes of coating material are visible.

Immagine microscopica di usura dell'utensile per adesione riscontrata su GJL-200 (vedi a) e b)) e su GJS700 (vedi c) and d)). Per i provini ricoperti con HDG/Z100 i grandi scagliature tipiche dello zinco sono visibili sulla superficie dell'utensile (segnati in rosso). Per i provini ricoperti con HDG/ZM100 l'usura dell'utensile per adesione ha più l'aspetto disperso, anche su scala microscopica. Non sono visibili grosse scaglie aggregate del materiale di rivestimento.

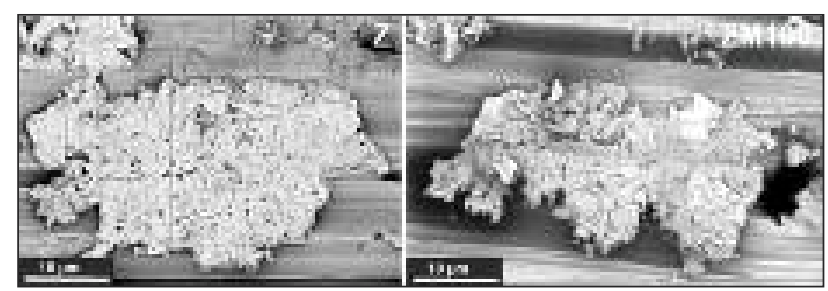

FIG. 12 Scanning electron microscopy image of adhesive tool wear. The morphology of the coating particles found on the tool is even different. HDG/Z (left side) forms flattened particles with little substructure. Scratches from subsequent drawing operations are visible on top of the particle, indicating that the transferred coating material is rather soft so that it can be influenced by subsequent drawing operations. In contrast, the HDG/ZM particle (right) shows a more fuzzy substructure. No scratches are visible from subsequent drawing operations.

Immagine SEM di usura dell'utensile per adesione. La morfologia delle particelle di rivestimento riscontrata sull'utensile è ancora diversa. HDG/Z (a sinistra) forma particelle appiattite con una piccolo sottostruttura. Graffi dovuti a successive operazioni di imbutitura sono visibili sopra le particelle, e indicano che il materiale di rivestimento trasferito è piuttosto tenero e può quindi essere condizionato da successive operazioni di imbutitura. Al contrario le particelle di HDG/ZM (destra) mostrano una sottostruttura più sfilacciato. Non sono visibili graffi dovuti a successive operazioni di imbutitura. 
rall amount of zinc found on the tool and to quantitatively compare the amount of transferred material. Zinc amounts of $0.669 \mathrm{mg}$ and $0.083 \mathrm{mg}$ were found respectively for HDG/Z and HDG/ZM on the GJL-200 tool. A total of $0.313 \mathrm{mg}$ Zn was found for HDG/Z and $0.267 \mathrm{mg} \mathrm{Zn}$ for HDG/ZM on the GJS-700 tool. This means that the morphology of the coating material on the tool is different and the overall amount was less for HDG/ZM than for HDG/Z.

\section{CONCLUSION}

Tribology and tool wear in the case of HDG/ZM turned out to have advantages over those of HDG/Z on cold rolled steel. The measured friction coefficient is slightly lower for HDG/ZM in the strip draw test as well as for forming model parts. In the strip draw test, HDG/ZM shows a higher processing window for drawing, for oiling with a prelube as well as for using a pure corrosion protection oil. However the difference from HDG/Z is not so large that profound changes in press parameters have to be made before HDG/ZM is used. This becomes even more visible when model parts are formed. Differences in tribology are more clearly visible for corrosion protection oil, and prelube oiling tends to smoothen tribological differences. At slow draw speeds, which are always found at the end of the draw process right before the part is fully formed, HDG/ZM has some tribologic advantages in both types of oiling. This may be especially helpful for critical parts that crack right at the end of a drawing process.

The tool wear tests were split into a tool abrasion test and an adhesive tool wear test. Tool abrasion was tested by using the SEP1160 tool abrasion test in the strip draw test and was found to be comparable to the tool abrasion of HDG/Z. This is an important result because the hardness of the HDG/ZM coating is higher than the values obtained for HDG/Z (70-90 HV0.02 vs. 130160 HV0.02 - see introduction). The adhesive tool wear was also tested in the strip draw test and was found to be less than for HDG/Z, both in amount of transferred coating material and in flaking. In the case of HDG/Z, the well known zinc flakes were found on the tool. The flakes were completely absent in the case of HDG/ZM. The morphology of the transferred material looks more powdery, and no big agglomerated coating particles were found.
The microscopic structure of the transferred particles looks more fuzzy and less influenced by subsequent drawing operations. This could be caused by the higher degree of hardness in the HDG/ZM coating material.

These results make HDG/ZM a promising alternative to HDG/Z, especially for complex parts with increased cracking tendency at the end of the drawing process and when galling cannot be sufficiently prevented under present conditions. The decreased flaking tendency observed in HDG/ZM can avoid pimple formation on critical parts in the deep drawing process. The potential advantages of HDG/ZM are thus not only improved corrosion performance but also superior deep drawing properties and tool wear.

\section{ACKNOWLEDGMENTS}

Financial support from the Austrian Federal Government (in particular from the Bundesministerium für Verkehr, Innovation und Technologie and the Bundesministerium für Wirtschaft und Arbeit), represented by Österreichische Forschungsförderungsgesellschaft $\mathrm{GmbH}$, is gratefully acknowledged.

\section{REFERENCES}

1) J. FADERL, G. ANGELI, G. LUCKENEDER, A. TOMANDL, Proc. 2nd International European Conference on Steels in Cars and Trucks, Wiesbaden, (2008)

2) J. HAGLER, G. ANGELI, D. EBNER, G. LUCKENEDER, M. FLEISCHANDERL, M. SCHATZL, Proc. 5th European Conference on Steel and Composite Structures, Graz, (2008)

3) W. WARNECKE, G. ANGELI, T. KOLL, E. NABBEFELD-ARNOLD, Proc. STAHL 2008, Düsseldorf, (2008)

4) S. SCHÜRZ, M. FLEISCHANDERL, G. LUCKENEDER, K. PREIS, T. HAUNSCHMIED, G. MORI, A.C. KNEISSL, Corrosion Science, 51, (2009), p.2355.

5) S. SCHÜRZ, G.H. LUCKENEDER, M. FLEISCHANDERL, P. MACK, H. GSALLER, A.C. KNEISSL, G. MORI, Corrosion Science, 52, (2010), p.3271.

6) E. DE BRUYCKER, "Zn-Al-Mg Alloy Coatings: Thermodynamic Analysis and Microstructure-Related Properties”, Ph.D. Thesis, University Gent, (2005)

7) SEP1160 "Evaluation of Weldable Corrosion Protection Primers for the Automotive Industry Part 8: Tool Wear Behavior", VDEh German Iron and Steel Assoziation (Dec. 2008)

\section{Abstract \\ Lamiere in acciaio zincate a caldo con ZnAlMg - Tribologia e attrito dell'utensile}

Parole chiave: rivestimenti - tribologia - acciaio

Negli ultimi anni i rivestimenti di leghe di magnesio zinco su acciaio laminato a freddo sono stati oggetto di studi approfonditi per le loro potenzialità nel fornire una migliore protezione contro la corrosione rispetto ai rivestimenti di zinco puro [1]. Tuttavia per consentirne un maggiore impiego nel settore automobilistico, è necessario approfondire anche il loro comportamento tribologico. Nel presente lavoro le potenzialità tribologiche di lamiere di acciaio zincate a caldo con ZnAlMg (HDG / ZM) sono state studiate in termini di caratteristiche di scorrimento, di attrito adesivo e abrasivo dell'utensile e sono state confrontate con un materiale di riferimento zincato a caldo (HDG / Z). Sono state eseguite diverse prove tribologiche. Il coefficiente di attrito è stato determinato direttamente effettuando prove di strip drawing a una pressione di contatto costante. La caratteristica di imbutitura è stata testata mediante formatura di modelli a tazza. Ciascuna delle prove tribologiche è stata condotta utilizzando due diversi oli, un olio puro di protezione contro la corrosione e un olio Prelube. L'usura con utensili abrasivi è stata studiata secondo quanto prescritto nella norma SEP1160. L'usura con utensili per adesione (grippaggio) è stata caratterizzata su diversi materiali da utensile e è stata confrontata con i risultati otteniti per il materiale di riferimento galvanizzato a caldo.

Le lamiere HDG / ZM hanno mostrato un comportamento all'attrito, nella prova strip drawing, migliorato rispetto al classico materiale di riferimento galvanizzazione a caldo per immersione del. L'usura con utensile da abrasione è paragonabile a quella del materiale HDG / Z, tuttavia, il grippaggio è risultato essere inferiore rispetto allo zinco puro, e anche la morfologia del materiale di rivestimento trasferito sullo strumento durante l'imbutitura risulta essere diversa. Questo rende l'HDG / / ZM un sistema interessante non solo per quanto riguarda la corrosione, ma anche in termini di tribologia, offrendo così evidenti vantaggi in termini di formabilità. 